\title{
Predictors of Aspiration Pneumonia: How Important Is Dysphagia?*
}

\author{
Susan E. Langmore, $\mathrm{PhD},{ }^{1,2}$ Margaret S. Terpenning, MD, ${ }^{1,3}$ Anthony Schork, $\mathrm{PhD},{ }^{4}$ Yinmiao Chen, $\mathrm{MS},{ }^{4}$ \\ Joseph T. Murray, MA, ${ }^{1}$ Dennis Lopatin, $\mathrm{PhD},{ }^{5}$ and Walter J. Loesche, $\mathrm{DMD}, \mathrm{PhD}^{5}$ \\ ${ }^{1}$ Veterans Affairs Medical Center, Ann Arbor, Michigan, ${ }^{2}$ School of Dentistry, Department of Oral Medicine, Pathology, and Surgery, ${ }^{3}$ School of \\ Medicine, Department of Internal Medicine, Division of Geriatric Medicine, ${ }^{4}$ School of Public Health, and ${ }^{5}$ School of Dentistry, Department of \\ Biologic and Materials Science, University of Michigan, Ann Arbor, Michigan, USA
}

\begin{abstract}
Aspiration pneumonia is a major cause of morbidity and mortality among the elderly who are hospitalized or in nursing homes. Multiple risk factors for pneumonia have been identified, but no study has effectively compared the relative risk of factors in several different categories, including dysphagia. In this prospective outcomes study, 189 elderly subjects were recruited from the outpatient clinics, inpatient acute care wards, and the nursing home care center at the VA Medical Center in Ann Arbor, Michigan. They were given a variety of assessments to determine oropharyngeal and esophageal swallowing and feeding status, functional status, medical status, and oral/dental status. The subjects were followed for up to 4 years for an outcome of verified aspiration pneumonia. Bivariate analyses identified several factors as significantly associated with pneumonia. Logistic regression analyses then identified the significant predictors of aspiration pneumonia. The best predictors, in one or more groups of subjects, were dependent for feeding, dependent for oral care, number of decayed teeth, tube feeding, more than one medical diagnosis, number of medications, and smoking. The role that each of the significant predictors might play was described in relation to the pathogenesis of aspiration pneumonia. Dysphagia was concluded to be an important risk for aspiration pneumonia, but generally not sufficient to cause pneumonia unless other risk factors are present as well. A dependency upon others for feeding emerged as the dominant risk factor, with an odds ratio
\end{abstract}

\footnotetext{
*This work was supported by Program Project Grant DE-09142 from the National Institute of Dental Research.

Correspondence to: Susan E. Langmore, Ph.D., Audiology \& Speech Pathology Department (126), VA Medical Center, 2215 Fuller Road, Ann Arbor, MI 48105, USA
}

of 19.98 in a logistic regression model that excluded tube-fed patients.

Key words: Pneumonia - Aspiration - Functional status - Medical, oral, dental status - Deglutition Deglutition disorders.

Aspiration pneumonia is a major problem for the elderly, leading to hospitalization, costly care, and at times death. It accounts for anywhere from $13 \%$ to $48 \%$ of all infections in nursing home residents [1,2] and is the second most common type of nosocomial infection in hospitalized patients, after urinary tract infections [3]. The overall mortality rate ranges from $20 \%$ to $50 \%$, with a rate as high as $80 \%$ reported in some studies [4-8]. From these reports, factors that are commonly cited as being associated with pneumonia are advanced age, residing in an environment such as an institutional setting where risk of infection is higher, predisposing medical conditions, reduced mental status, reduced functional status, tube feeding, gastroesophageal reflux, poor nutritional status, oropharyngeal colonization of pathogenic bacteria, reduced pulmonary clearance, and immunocompromise [5,9-20].

Many recent studies have shown a relationship between pneumonia and oropharyngeal dysphagia with aspiration of food or liquid [21-30]. Since dysphagia predisposes to aspiration, the relationship between dysphagia and aspiration pneumonia might appear obvious, but evidence for this has not always been found [31-33]. In fact, several studies of tube-fed patients who are taking no food or liquid by mouth have shown that tube feeding is associated with a higher rate of pneumonia than in patients who are eating [19,23,28,30,31,33,34]. A large body of literature has focused on the association between gastroesophageal reflux and aspiration [18,35- 
42]. In clinical settings, "aspiration precautions" such as elevating the head of the bed are commonly carried out to prevent aspiration of refluxed material. When tube-fed patients develop pneumonia, aspiration of refluxed tube feedings are often believed to have caused the problem. Finally, a large number of studies of the bacteriology of aspiration pneumonia suggest that the combination of colonization of the oropharynx with bacterial pathogens and microaspiration of saliva containing these bacteria may be the most common source of aspiration pneumonia [43-51].

Research on prevention of aspiration pneumonia should be given the same import as those investigations that have focused on treatment of pneumonia with antibiotics. If the cause of the pneumonia is not found and corrected, it will likely recur. One problem with preventive studies is controlling the many risk factors that have been identified. Most studies have focused on risk factors related to dysphagia or to the hospital environment. Though these studies are informative, their limited nature does not allow us to appreciate the relative importance of the other risk factors. This step is critical when focusing on intervention programs to reduce the incidence of pneumonia, as clinical outcomes will be more effective if we target the most important risk factors in all critical areas. A few studies have applied specific treatments such as swallowing therapy [52-56], but with mixed results, perhaps because other risk factors were not addressed.

In this prospective study, risk factors that included dysphagia and feeding status, functional status, medical status, and oral/dental status were evaluated for their contribution to the development of aspiration pneumonia in elderly patients who were acutely ill and hospitalized, in nursing homes, or who were outpatients and fairly healthy.

\section{Materials and Methods}

\section{Subjects}

One hundred eighty-nine subjects were recruited from the outpatient clinics, inpatient acute care medical wards, and the nursing home care center at the VA Medical Center, Ann Arbor, Michigan. Intensive Care Unit patients were not recruited and relatively few postsurgical patients were recruited. All subjects were male and 60 years of age or older. One hundred and sixty subjects had medical diagnoses which included stroke, other neurologic problem, gastrointestinal (GI) disease, diabetes, chronic obstructive pulmonary disorder (COPD), and/or congestive heart failure $(\mathrm{CHF})$. Most subjects had more than one of these problems (112 subjects) and 29 subjects had none of these problems and were identified as our control subjects. No subjects were enrolled who had current or past history of head and neck cancer. Complaint of oropharyngeal dysphagia was not an inclusionary or exclusionary criteria for enrollment in the study. All subjects who enrolled in the study con- sented freely, in writing, and in accordance with written guidelines and full approval of the Subcommittee on Human Studies at the VA Medical Center, Ann Arbor.

\section{Procedures}

After agreeing to participate, each subject was given the following procedures: a clinical examination of oropharyngeal swallowing function; a fluoroscopic examination of oropharyngeal swallowing function; three scintigraphy examinations to assess esophageal clearance, gastroesophageal reflux (GER) and pulmonary aspiration of gastric refluxed material. In addition, about half the subjects also had a Fiberoptic Endoscopic Evaluation of Swallowing (FEES ${ }^{\circledR}$ ), modified from its original version [57], to assess pharyngeal swallowing and laryngeal competence. These swallowing examinations were performed according to standard protocols developed by the investigators and are available upon request. A thorough dental examination was performed that included the collection of resting and stimulated salivary flow and throat cultures, and an in-depth interview covering medical and dental conditions was conducted [58]. Saliva and throat samples were cultured aerobically and anaerobically and these results will be published separately. Medical and functional status information was recorded from observation of the patient or from the medical chart. After these initial procedures, the subjects were followed for an outcome of pneumonia, death, or until their failure to return for further examinations. The interview, dental examination, clinical swallowing examination, and saliva collection were repeated annually, with a fluoroscopic examination done if swallowing status was suspected to have changed from baseline.

If pneumonia was suspected or reported in the medical chart, a pneumonia panel was convened to make a determination of the diagnosis. The panel consisted of a pulmonologist, a geriatrician, and a cardiologist. Three criteria were used in defining the diagnosis: elevated white blood cell count (12,000 or above); fever (temperature $>100.5 \mathrm{~F}$ ); and new infiltrate on the chest radiograph, with most weight given to radiographic evidence of a new infiltrate. Patients were considered to have pneumonia only when there was consensus of the panel. Patients with new congestive heart failure were excluded, as well as any patient with a nonaspiration-related pneumonia, such as hematogenous pneumonia.

\section{Data Analyses}

The outcome of interest in this study was aspiration pneumonia. Patients were identified as $+/-$ pneumonia, depending on the consensus reached by the pneumonia panel. All independent variables were submitted to bivariate analyses to determine those variables significantly associated with pneumonia. All variables that had attained a $p$ level of $\leq 0.10$ in bivariate analyses were subjected to multiple logistic regression analyses. Four models were developed to find the best predictors of aspiration pneumonia in different categories of subjects. In two models, dental variables were included as independent variables, and thus, all edentulous subjects were deleted from consideration. In the other analyses, dependency for feeding was included as a functional status variable and in these analyses, all tube-fed patients were excluded. Data entry was completed in a Fourth Dimension data base, and data analysis was performed using the SAS statistical package.

Definitions and Measures. Measures of medical status were age, stroke, other neurologic disease, COPD, diabetes, CHF, GI disease, more than one of these diagnoses, number of diagnoses, use of any medication, number of medications, now smoking, site of entry: (1) outpatient, (2) acute care inpatient, (3) nursing home.

Measures of functional status were mental status: (1) alert and fully aware, (2) inattentive, distractable, or confused, (3) lethargic or 
somnolent; activity level: (1) bed bound, (2) up for meals/bath, (3) up for one half day, (4) up for less than one half day; dependent for oral care: (1) independent, (2) independent with device, (3) needs some assistance, (4) needs full assistance; dependent for feeding: (1) independent, (2) independent with device, (3) needs some assistance, (4) needs full assistance.

Measures of pharyngeal swallowing, visualized radiographically and/or endoscopically, were defined as pharyngeal delay: time elapsed from when the bolus head passed the base of tongue/ramus of mandible until final hyoid elevation began; spillage: lowest point of bolus head when hyoid elevation began-(0) still above base of tongue/ ramus of mandible, (1) at base of tongue/ramus of mandible, (2) to pit of valleculae, (3) to midpoint of aryepiglottic fold, (4) to pit of pyriform; residue: material left in the hypopharynx after the swallow- $(0)$ none, (1) mild, in pyriforms or valleculae, (2) mild-to-moderate and weak swallow detected, (3) moderate to severe residue throughout the pharynx and obviously weak swallow, (4) severe residue throughout and extremely weak or absent swallow: aspiration: material (food, liquid, secretions) observed to pass below the level of the vocal folds; silent aspiration: patient did not respond to an event of aspiration with a spontaneous cough: presence of dysphagia: one or more of the following: (1) documented aspiration of food, liquid, or secretions, (2) pharyngeal delay of $>2$ SD above the mean of the control group, (3) spillage rating on puree consistency of 4 , or (4) residue rating of 4 on puree consistency.

Esophageal motility and GER, identified from nuclear medicine scintigraphy examinations, were defined as esophageal clearance: (1) percent of material cleared from the esophagus at 10 and $15 \mathrm{sec}$ and (2) transit time of major part of bolus through esophagus; GER: (1) presence of GER anytime during the study, (2) GER to level of upper esophagus, (3) GER persisted spontaneously after the binder was removed.

Measure of feeding/nutritional intake were presence of tube feeding at time of study and presence of tube feeding at time of pneumonia.

Measures of oral/dental status were similar to those described in Loesche et al. [58] and included oral cavity: clean/dirty as rated by clinical examiner; rating of secretions in mouth: (1) normal, (2) dry, or (3) excess, as rated by clinical examiner; minor salivary gland output: degree of wetness as measured with a Periotron in $\mathrm{ml} / \mathrm{min}$; stimulated saliva flow: ml suctioned over a 5-min period; complaint of xerostomia: yes/no; use of any xerostomic medications: yes/no; number of xerostomic medications; papillary bleeding score; plaque index; plaque BANA score; periodontal disease score; number of missing teeth; number of sound teeth; number of restored teeth; number of decayed teeth; having full/partial dentures; having full dentures-upper/lower; wearing dentures only when eating: yes/no; frequency of brushing teeth: (1) never, (2) occasionally to $2-3 /$ week, (3) at least once a day; frequency of flossing teeth: (1) never, (2) occasionally to $2-3 /$ week, (3) at least once a day; frequency of visiting hygienist: (1) never, (2) occasionally, (3) at least once a year.

\section{Results}

Of the 189 subjects followed to outcome, by consensus of the panel, 41 developed aspiration pneumonia for an overall incidence rate of $21.7 \%$. Average time to development of pneumonia after baseline testing was 329 days, or 11 months, and median length of time was 174 days or 6 months, with an overall range from 0 to 1,242 days (3.4 years). Average age of the subjects who devel- oped aspiration pneumonia was 71 years compared with 69.5 years for the subjects who did not develop pneumonia.

Table 1 summarizes the distribution of certain medical conditions for subjects who did or did not develop aspiration pneumonia, stratified as to living status at time of entry into the study, i.e., 93 inpatients, 55 outpatients, and 41 nursing home patients. The highest incidence of aspiration pneumonia occurred in the nursing home patients (44\%), with $19 \%$ of the inpatients and only $9 \%$ of the outpatients experiencing pneumonia. When looking at patients by medical diagnosis, $21 / 78$ or $27 \%$ of the patients with stroke, $14 / 43$ or $33 \%$ with other neurologic disease, and $32 \%$ of the patients with either COPD or CHF or GI disease developed aspiration pneumonia. Those subjects with both COPD and GI disease had nearly a $50 \%$ incidence of pneumonia. An increased incidence of pneumonia occurred in subjects with multiple medical problems, whereas none of the subjects who were free of these medical problems developed pneumonia. Thirty-two percent of the subjects who developed aspiration pneumonia smoked and they averaged 10 medications compared with 7.6 in subjects without pneumonia.

Of the subjects with aspiration pneumonia, $81 \%$ had oropharyngeal dysphagia, 58\% aspirated liquid, $27 \%$ aspirated food, and $50 \%$ aspirated secretions. Further, $28 \%$ had documented GER and 27\% were tube fed (Table 2). These proportions were all significantly higher than the corresponding values found in subjects without aspiration pneumonia except for the presence of GER, which was actually higher in the group that did not get pneumonia.

The inpatients and nursing home groups had the highest proportion of subjects with dysphagia and who aspirated. Inpatients who developed aspiration pneumonia were significantly more likely to exhibit pharyngeal delay with both liquids and pureed foods and to aspirate food than inpatients who did not develop aspiration pneumonia (Table 2).

The proportions of subjects who developed aspiration pneumonia were significantly more likely to be bed bound (16\%) and to exhibit reduced activity levels (43\%) compared with subjects who did not develop aspiration pneumonia (Table 3). Forty-one percent of the subjects who developed aspiration pneumonia were dependent on others to feed them compared with only $6 \%$ of the subjects without aspiration pneumonia. This dependency was also reflected in their need for oral care. All individuals with these dependencies were in the nursing home or inpatient groups (Table 3 ).

There were 76 edentulous cases and 113 dentate cases in our study group. There was a significant increase in the number of decayed teeth in those with aspiration 
Table 1. Bivariate analyses for medical status factors associated with pneumonia: summary by site of entry

\begin{tabular}{|c|c|c|c|c|c|c|c|c|}
\hline \multirow[b]{2}{*}{ Medical status parameters } & \multicolumn{2}{|l|}{$\begin{array}{l}\text { All subjects } \\
(n=189)\end{array}$} & \multicolumn{2}{|l|}{$\begin{array}{l}\text { Outpatient } \\
(n=55)\end{array}$} & \multicolumn{2}{|l|}{$\begin{array}{l}\text { Inpatient } \\
(n=93)\end{array}$} & \multicolumn{2}{|c|}{$\begin{array}{l}\text { Nursing home } \\
(n=41)\end{array}$} \\
\hline & $\begin{array}{l}- \text { Pneu } \\
(n=148)\end{array}$ & $\begin{array}{l}+ \text { Pneu } \\
(n=41)\end{array}$ & $\begin{array}{l}- \text { Pneu } \\
(n=50)\end{array}$ & $\begin{array}{l}+ \text { Pneu } \\
(n=5)\end{array}$ & $\begin{array}{l}\text {-Pneu } \\
(n=75)\end{array}$ & $\begin{array}{l}+ \text { Pneu } \\
(n=18)\end{array}$ & $\begin{array}{l}- \text { Pneu } \\
(n=23)\end{array}$ & $\begin{array}{l}+ \text { Pneu } \\
(n=18)\end{array}$ \\
\hline Mean age (years) & 69.5 & 71.3 & 70.7 & 66.4 & 68.5 & 67.7 & 69.8 & $75.1^{\mathrm{a}}$ \\
\hline Stroke & $39 \%$ & $51 \%$ & $6 \%$ & $0 \%$ & $55 \%$ & $61 \%$ & $57 \%$ & $56 \%$ \\
\hline Other neurologic disease & $26 \%$ & $34 \%$ & $4 \%$ & $60 \%^{\mathrm{b}}$ & $39 \%$ & $39 \%$ & $35 \%$ & $23 \%$ \\
\hline COPD & $32 \%$ & $56 \%^{\mathrm{b}}$ & $14 \%$ & $40 \%$ & $47 \%$ & $50 \%$ & $26 \%$ & $67 \%^{\mathrm{b}}$ \\
\hline $\mathrm{CHF}$ & $21 \%$ & $37 \%^{\mathrm{a}}$ & $6 \%$ & $40 \%$ & $27 \%$ & $28 \%$ & $35 \%$ & $44 \%$ \\
\hline GI disease & $30 \%$ & $53 \%^{\mathrm{b}}$ & $30 \%$ & $40 \%$ & $27 \%$ & $44 \%$ & $43 \%$ & $65 \%$ \\
\hline None of these diagnoses & $20 \%$ & $0 \%^{\mathrm{b}}$ & $56 \%$ & $0 \%{ }^{\mathrm{a}}$ & $1 \%$ & $0 \%$ & $0 \%$ & $0 \%$ \\
\hline More than one diagnosis & $54 \%$ & $78 \%^{\mathrm{b}}$ & $20 \%$ & $60 \%$ & $68 \%$ & $67 \%$ & $83 \%$ & $94 \%$ \\
\hline Number of medications & 7.6 & $10.0^{\mathrm{b}}$ & 5.5 & 7.3 & 8.3 & 9.2 & 9.8 & 11.4 \\
\hline Number of medical diagnoses & 1.80 & $2.6^{\mathrm{b}}$ & 0.8 & $2.2^{\mathrm{b}}$ & 2.3 & 2.6 & 2.5 & 2.8 \\
\hline Now smoking & $22 \%$ & $32 \%$ & $14 \%$ & $0 \%$ & $29 \%$ & $33 \%$ & $17 \%$ & $41 \%$ \\
\hline
\end{tabular}

${ }^{a}$ Difference between subjects with and without pneumonia is significant $p=0.01-0.05$.

${ }^{\mathrm{b}}$ Difference between subjects with and without pneumonia is significant $p<0.01$.

Note: Some cells may have an $n$ of less than total indicated in column.

Table 2. Bivariate analyses for swallowing, GE reflux, and nutritional intake factors associated with pneumonia: summary by site of entry

\begin{tabular}{|c|c|c|c|c|c|c|c|c|}
\hline \multirow[b]{2}{*}{$\begin{array}{l}\text { Swallowing/nutritional } \\
\text { intake parameters }\end{array}$} & \multicolumn{2}{|l|}{$\begin{array}{l}\text { All subjects } \\
(n=189)\end{array}$} & \multicolumn{2}{|l|}{$\begin{array}{l}\text { Outpatient } \\
(n=55)\end{array}$} & \multicolumn{2}{|l|}{$\begin{array}{l}\text { Inpatient } \\
(n=93)\end{array}$} & \multicolumn{2}{|c|}{$\begin{array}{l}\text { Nursing home } \\
(n=41)\end{array}$} \\
\hline & $\begin{array}{l}\text {-Pneu } \\
(n=148)\end{array}$ & $\begin{array}{l}+ \text { Pneu } \\
(n=41)\end{array}$ & $\begin{array}{l}\text {-Pneu } \\
(n=50)\end{array}$ & $\begin{array}{l}+ \text { Pneu } \\
(n=5)\end{array}$ & $\begin{array}{l}\text {-Pneu } \\
(n=75)\end{array}$ & $\begin{array}{l}+ \text { Pneu } \\
(n=18)\end{array}$ & $\begin{array}{l}\text {-Pneu } \\
(n=23)\end{array}$ & $\begin{array}{l}+ \text { Pneu } \\
(n=18)\end{array}$ \\
\hline \multicolumn{9}{|l|}{ Swallowing: GE reflux } \\
\hline Presence of dysphagia-fluoro/FEES & $47 \%$ & $81 \%^{\mathrm{b}}$ & $28 \%$ & $50 \%$ & $63 \%$ & $82 \%$ & $41 \%$ & $88 \%^{\mathrm{a}}$ \\
\hline Mean delay with liquid (fluoro) (sec) & 0.1 & 0.7 & 0.2 & -0.3 & -0.1 & $1.2^{\mathrm{a}}$ & 0.2 & -0.2 \\
\hline Mean delay with purée (fluoro) (sec) & 0.4 & $0.9^{\mathrm{a}}$ & 0.1 & -0.2 & 0.6 & $1.2^{\mathrm{a}}$ & 0.2 & 0.6 \\
\hline Low spillage point with purée (fluoro) & $0 \%$ & $12 \%^{\mathrm{b}}$ & $0 \%$ & $0 \%$ & $0 \%$ & $19 \%^{\mathrm{b}}$ & $0 \%$ & $0 \%$ \\
\hline High residue rating-liquid (fluoro) & $6 \%$ & $18 \%$ & $5 \%$ & $0 \%$ & $4 \%$ & $21 \%$ & $10 \%$ & $14 \%$ \\
\hline High residue rating_-purée (fluoro) & $4 \%$ & $20 \%{ }^{\mathrm{a}}$ & $0 \%$ & $50 \%{ }^{\mathrm{a}}$ & $7 \%$ & $25 \%$ & $5 \%$ & $0 \%$ \\
\hline Aspiration of liquid-fluoro/FEES & $37 \%$ & $58 \%^{\mathrm{a}}$ & $16 \%$ & $0 \%$ & $53 \%$ & $59 \%$ & $32 \%$ & $71 \%$ \\
\hline Aspiration of blood-fluoro/FEES & $9 \%$ & $27 \%^{\mathrm{a}}$ & $9 \%$ & $50 \%$ & $9 \%$ & $35 \%{ }^{\mathrm{a}}$ & $9 \%$ & $0 \%$ \\
\hline Aspiration of secretions-FEES & $31 \%$ & $50 \%$ & $7 \%$ & $100 \%$ & $57 \%$ & $44 \%$ & $22 \%$ & $50 \%$ \\
\hline $\begin{array}{l}\text { Transit time through esophagus (sec) } \\
\text { Scintigraphy }\end{array}$ & 14.4 & 23.9 & 10.5 & - & 15.8 & 19.3 & 33.3 & 47.0 \\
\hline Presence of GE reflux-Scintigraphy & $29 \%$ & $24 \%$ & $32 \%$ & $0 \%$ & $25 \%$ & $17 \%$ & $40 \%$ & $50 \%$ \\
\hline \multicolumn{9}{|l|}{ Nutritional intake } \\
\hline Tube feeding at time of swallow study & $8 \%$ & $20 \%^{\mathrm{a}}$ & $0 \%$ & $0 \%$ & $11 \%$ & $28 \%$ & $0 \%$ & $17 \%$ \\
\hline Tube feeding before pneumonia & $9 \%$ & $27 \%^{\mathrm{b}}$ & $0 \%$ & $20 \%$ & $13 \%$ & $41 \%^{\mathrm{a}}$ & $0 \%$ & $13 \%$ \\
\hline
\end{tabular}

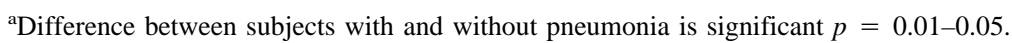

${ }^{\mathrm{b}}$ Difference between subjects with and without pneumonia is significant $p<0.01$.

Note: Some cells may have an $n$ of less than total indicated in column.

pneumonia, which was observed in individuals from all recruitment sites (Table 4). Significantly more dentate patients who reported that they occasionally or never brushed their teeth were likely to develop aspiration pneumonia. Being edentulous had no effect on the development of aspiration pneumonia. There was no difference in the rate of stimulated salivary flow between individuals who did and those who did not develop aspiration pneumonia. Most subjects complained of a xero- stomia sometime during the day, but neither this complaint nor the usage of xerogenic medications could be significantly associated with aspiration pneumonia. Bacteriologic findings will be published separately.

When examining the variables significantly associated with pneumonia by site of entry, some differences between groups were noted. Significant variables for outpatients were number of decayed teeth, high residue rating with pureed food, presence of other neurologic dis- 
Table 3. Bivariate analyses for functional status factors associated with pneumonia: summary by site of entry

\begin{tabular}{|c|c|c|c|c|c|c|c|c|}
\hline \multirow[b]{2}{*}{ Functional status parameters } & \multicolumn{2}{|l|}{$\begin{array}{l}\text { All subjects } \\
(n=189)\end{array}$} & \multicolumn{2}{|l|}{$\begin{array}{l}\text { Outpatient } \\
(n=55)\end{array}$} & \multicolumn{2}{|l|}{$\begin{array}{l}\text { Inpatient } \\
(n=93)\end{array}$} & \multicolumn{2}{|c|}{$\begin{array}{l}\text { Nursing home } \\
(n=41)\end{array}$} \\
\hline & $\begin{array}{l}\text {-Pneu } \\
(n=148)\end{array}$ & $\begin{array}{l}+ \text { Pneu } \\
(n=41)\end{array}$ & $\begin{array}{l}\text {-Pneu } \\
(n=50)\end{array}$ & $\begin{array}{l}+ \text { Pneu } \\
(n=5)\end{array}$ & $\begin{array}{l}\text {-Pneu } \\
(n=75)\end{array}$ & $\begin{array}{l}+ \text { Pneu } \\
(n=18)\end{array}$ & $\begin{array}{l}\text {-Pneu } \\
(n=23)\end{array}$ & $\begin{array}{l}+ \text { Pneu } \\
(n=18)\end{array}$ \\
\hline Reduced activity level (not bedbound) & $96 \%$ & $84 \%^{\mathrm{a}}$ & $100 \%$ & $100 \%$ & $92 \%$ & $76 \%$ & $100 \%$ & $89 \%$ \\
\hline Reduced activity level (up $1 / 2$ day or less) & $24 \%$ & $43 \%{ }^{\mathrm{a}}$ & $2 \%$ & $50 \%$ & $39 \%$ & $59 \%$ & $13 \%$ & $28 \%$ \\
\hline Reduced activity level (bedbound) & $4 \%$ & $16 \%{ }^{\mathrm{a}}$ & $10 \%$ & $0 \%$ & $8 \%$ & $24 \%$ & $0 \%$ & $11 \%$ \\
\hline Reduced level of alertness (inattentive, lethargic) & $13 \%$ & $21 \%$ & $2 \%$ & $0 \%$ & $19 \%$ & $39 \%$ & $13 \%$ & $6 \%$ \\
\hline Dependent for oral care & $10 \%$ & $34 \%^{\mathrm{b}}$ & $0 \%$ & $0 \%$ & $14 \%$ & $56 \%{ }^{\mathrm{b}}$ & $13 \%$ & $17 \%$ \\
\hline Dependent for feeding & $6 \%$ & $41 \%^{b}$ & $0 \%$ & $0 \%$ & $6 \%$ & $46 \%^{b}$ & $13 \%$ & $53 \%^{\mathrm{a}}$ \\
\hline
\end{tabular}

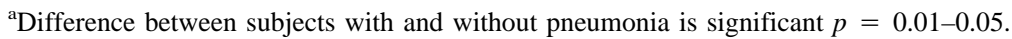

${ }^{\mathrm{b}}$ Difference between subjects with and without pneumonia is significant $p<0.01$.

Note: Some cells may have an $n$ of less than total indicated in column.

Table 4. Bivariate analyses for oral/dental factors associated with pneumonia: summary by site of entry

\begin{tabular}{|c|c|c|c|c|c|c|c|c|}
\hline \multirow[b]{2}{*}{ Oral/dental parameters } & \multicolumn{2}{|l|}{$\begin{array}{l}\text { All subjects } \\
(n=189)\end{array}$} & \multicolumn{2}{|l|}{$\begin{array}{l}\text { Outpatient } \\
(n=55)\end{array}$} & \multicolumn{2}{|l|}{$\begin{array}{l}\text { Inpatient } \\
(n=93)\end{array}$} & \multicolumn{2}{|c|}{$\begin{array}{l}\text { Nursing home } \\
(n=41)\end{array}$} \\
\hline & $\begin{array}{l}\text {-Pneu } \\
(n=148)\end{array}$ & $\begin{array}{l}+ \text { Pneu } \\
(n=41)\end{array}$ & $\begin{array}{l}\text {-Pneu } \\
(\mathrm{n}=50)\end{array}$ & $\begin{array}{l}+ \text { Pneu } \\
(n=5)\end{array}$ & $\begin{array}{l}\text {-Pneu } \\
(n=75)\end{array}$ & $\begin{array}{l}+ \text { Pneu } \\
(n=18)\end{array}$ & $\begin{array}{l}\text {-Pneu } \\
(n=23)\end{array}$ & $\begin{array}{l}\text { +Pneu } \\
(n=18)\end{array}$ \\
\hline Complaint of xerostomia & $76 \%$ & $74 \%$ & $65 \%$ & $80 \%$ & $83 \%$ & $60 \%$ & $78 \%$ & $83 \%$ \\
\hline No. of xerogenic medications & $69 \%$ & $75 \%$ & $64 \%$ & $75 \%$ & $67 \%$ & $83 \%$ & $87 \%$ & $69 \%$ \\
\hline Stimulated salivary flow (ml/min) & 0.56 & 0.57 & 0.74 & 0.54 & 0.43 & 0.47 & 0.56 & 0.65 \\
\hline Dirty mouth & $16 \%$ & $25 \%$ & $14 \%$ & $50 \%$ & $18 \%$ & $29 \%$ & $17 \%$ & $0 \%$ \\
\hline Brush teeth occasionally or never & $12 \%$ & $40 \%$ b & $3 \%$ & $25 \%$ & $21 \%$ & $60 \%$ & $9 \%$ & $36 \%$ \\
\hline Edentulous & $42 \%$ & $46 \%$ & $29 \%$ & $20 \%$ & $47 \%$ & $63 \%$ & $57 \%$ & $39 \%$ \\
\hline Number of decayed teeth & 2.4 & $5.2^{\mathrm{b}}$ & 1.2 & $4.0^{\mathrm{a}}$ & 3.5 & $7.2^{\mathrm{a}}$ & 2.5 & 4.6 \\
\hline Dry or excess secretions in mouth & $17 \%$ & $38 \%{ }^{\mathrm{a}}$ & $7 \%$ & $50 \%$ & $25 \%$ & $35 \%$ & $17 \%$ & $40 \%$ \\
\hline
\end{tabular}

${ }^{a}$ Difference between subjects with and without pneumonia is significant $p=0.01-0.05$.

${ }^{\mathrm{b}}$ Difference between subjects with and without pneumonia is significant $p<0.01$.

Note: Some cells may have an $n$ of less than total indicated in column.

ease, and absence of any of the monitored medical diagnoses. In the inpatient group several swallowing variables, the number of decayed teeth, and dependent for oral care were significantly associated with pneumonia. In the nursing home patients, the presence of COPD, dysphagia, and increasing age were significantly associated with pneumonia. Both the inpatients and nursing home patients showed a highly significant association of dependency for feeding with aspiration pneumonia (Tables 1-4).

Following the bivariate analyses, multiple logistic regression analyses were done to determine the best independent predictors of pneumonia. In designing models for logistic regression analysis, we regrouped the patients according to whether they were tube fed or had teeth, as these variables were not present in all subjects and could be important determinants of pneumonia. In the two models that included dependence for feeding as an independent variable, tube-fed patients were excluded, since by definition they could not be fed orally.
In the two models that included variables relating to dental status, all edentulous patients were excluded. In these models, the site of entry was added to the list of independent variables in order to retain information on the original groupings shown in Tables 1-4.

Table 5 summarizes the results of the multiple logistic regression analyses for the reordered groups of subjects. In the all-subjects model, where all subjects were included but the dental variables and dependent for feeding were not considered, the best predictors were tube fed before pneumonia $(\mathrm{OR}=3.031 ; \mathrm{p}=0.05)$ and dependent for oral care $(\mathrm{OR}=2.828$ (OR odds ratio); $p$ $=0.03)$. In the second model, where dependent for feeding was included for consideration but tube-fed patients and the dental variables were eliminated, dependent for feeding $(\mathrm{OR}=19.98 ; p=0.0001)$, now smoking $(\mathrm{OR}$ $=4.13 ; p=0.02)$, and number of medications $(\mathrm{OR}=$ $1.15 ; p=0.02$ ) emerged as the best predictors).

In the third model, dental variables were added to the list of independent variables to be analyzed and all 
Table 5. Significant predictors of pneumonia from multiple logistic regression analyses: odds ratio/95\% confidence interval/probability level

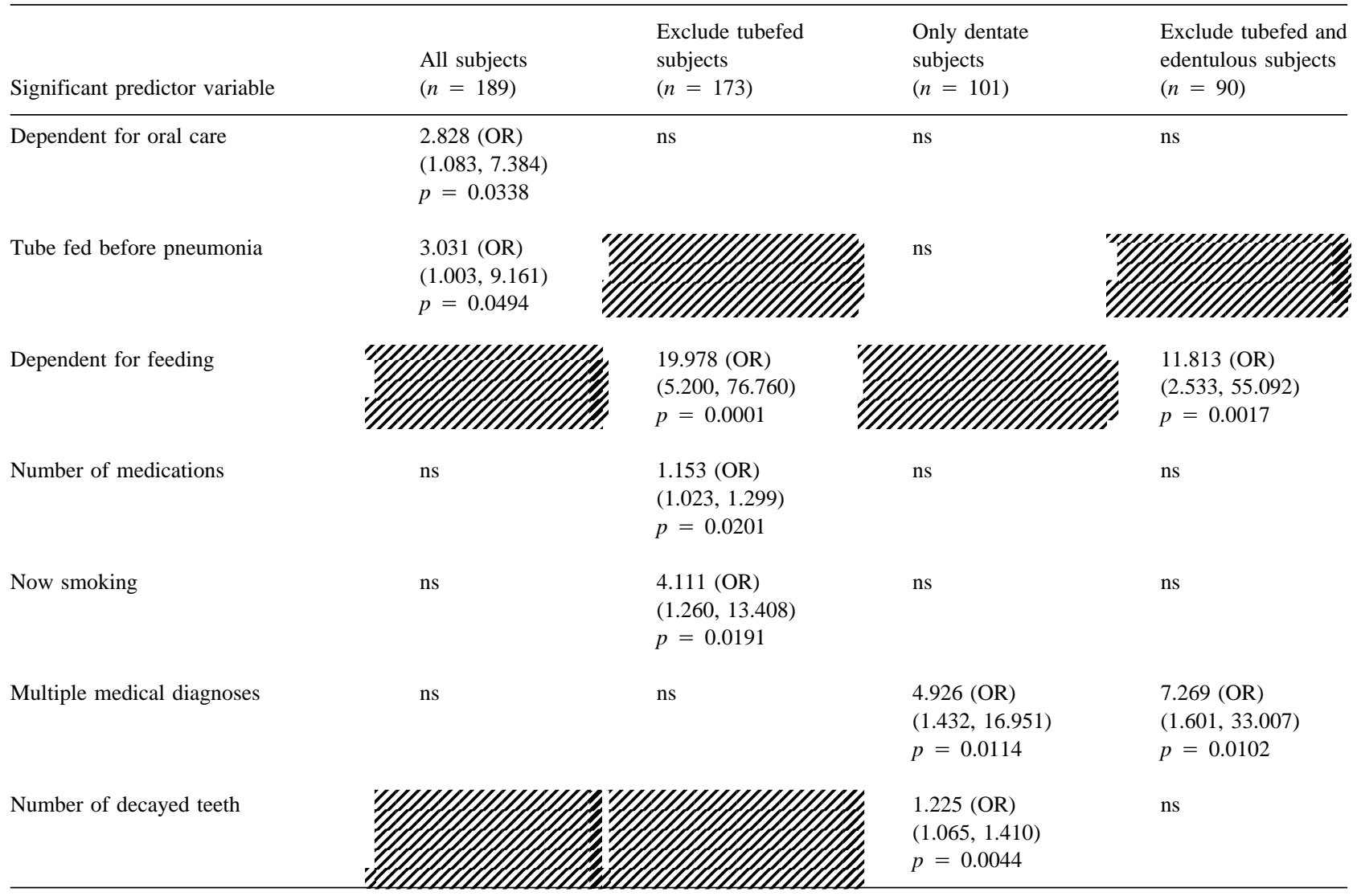

ns $=$ Not significant.

Shaded box $=$ not applicable for this subject group.

Numbers in ( ) are confidence interval.

edentulous patients were excluded, reducing the subject number to 100. Dependent for feeding was eliminated so that dentate tube-fed patients could be included. In this group, the best predictors of pneumonia were number of decayed teeth $(\mathrm{OR}=1.67 ; p=0.004)$ and multiple medical diagnoses $(\mathrm{OR}=8.02 ; 0=0.01)$. Finally, when tube-fed patients and edentulous patients were both eliminated from the subject pool, all variables could be considered. The best predictors of pneumonia in dentate oral feeders were dependent for feeding $(\mathrm{OR}=11.81 ; p$ $=0.002)$ and multiple medical diagnoses $(\mathrm{OR}=7.27$; $p=0.01)$.

\section{Discussion}

In this study, putative risk factors for aspiration pneumonia relating to functional status, medical/health status, oral/dental status, and swallowing/feeding status were examined in the same patients. Consistent with results of previous studies, many variables were found to be significantly associated with pneumonia. The advantage of the current study is that more categories of risk were included and variables relating to dysphagia were examined in detail.

\section{Variables Significantly Associated with Aspiration} Pneumonia in the Bivariate Analyses

Medical/Health Status. Though stroke and other neurologic diseases have historically been associated with a high incidence of aspiration pneumonia, we found that patients with COPD, GI disease, and CHF experienced a similar high rate (26\%-33\%). It was noteworthy that our subjects with both COPD and GI disease incurred the highest rate of pneumonia, i.e., $50 \%$ incidence rate. These findings are consistent with reports that patients with GI diseases are at increased risk for aspiration pneumonia [39-62], and that emphysema or chronic bronchitis is a common underlying disease, found in $15 \%-50 \%$ of all pneumonias $[63,64]$.

The highest incidence of pneumonia, i.e., $44 \%$, was found in the nursing home patients. This finding supports the work of Alvarez et. al [9], who have related a higher incidence of pneumonia to a more debilitated patient population with multiple underlying disease, ex- 
cessive medications, and poor functional status. Thus, though site of entry was not a significant predictor of pneumonia, it may have been highly correlated with several of our significant predictors that marked severity of illness or dependent functional status. Previous reports have suggested that advanced age is associated with an increase in pneumonia $[44,65]$, but this was not shown in our study, except in the nursing home subjects who tended to be older (Table 1).

Functional Status. In contrast to other reports $[45,66]$, we did not find reduced level of alertness to be associated with increased pneumonia. The two variables that measured independence for activities of daily living, i.e., dependent for feeding and dependent for oral care, were found to be highly significantly related to pneumonia. Several studies have reported dependent functional status to be associated with a high incidence of pneumonia $[9,12]$. Since level of independence for dressing, transferring, or other activities were not measured in this study, it cannot be said whether functional status in general was associated with pneumonia or whether dependence for eating and oral care are especially relevant for predisposing a person to pneumonia. However, Katz and Akpom [67] who developed the Index of Independence in Activities of Daily Living (ADL), found that there was a hierarchy of dependence, and that dependence for feeding was usually the last functional activity to succumb to dependence. If this held true for our subjects, many of them who were dependent for feeding would also have been dependent in other functional activities and were "severely dependent" persons.

Dysphagia and GE Reflux Status. The presence of dysphagia and aspiration were both found to be significantly related to pneumonia primarily in our subjects recruited from the acute care wards. Previous studies $[21,24,54]$ reported that aspiration of food had a higher association with aspiration pneumonia than did aspiration of thin liquid. Similarly, we found that aspiration of food was significantly more likely to be associated with pneumonia than was aspiration of liquid. Other aspects of dysphagia such as pharyngeal delay, low spillage point, and excess residue were also significantly related to aspiration pneumonia. One previous study has reported pharyngeal delay to be associated with pneumonia [23].

Delayed initiation of the swallow and weak swallow were most likely the physiologic causes of aspiration in most of our subjects. Delayed initiation of the swallow, or pharyngeal delay, is often associated with spillage of material into the hypopharynx and sometimes into the airway, just before or at the onset of the pharyngeal swallow. Similarly, excess residue is generally the result of a weak swallow and incomplete bolus clearance. The excess material remains in the hypopharynx after the swallow and can fall into the airway when the person resumes breathing. Both of these patterns have been reported to be significant predictors of aspiration [68]. It is also noteworthy that delayed initiation and excess residue were only significant as they occurred with pureed food, but not with liquids. This suggests that when these patterns were associated with aspiration of food, it was potentially more harmful than when it was associated with liquids and was more likely to lead to pneumonia.

The current study also found that aspiration of secretions and excess secretions in the mouth were both significantly associated with pneumonia in our dentate subjects. Very few previous studies have considered the potential importance of aspirated secretions, but Murray et al. [69] and Harkness et al. [11] independently reported this factor to be a sensitive predictor of aspiration and/or aspiration pneumonia.

Although the present study was not designed to compare the sensitivity of fluoroscopy and endoscopy (FEES) for detecting findings, it was noted that the two instrumental procedures had a high rate of agreement. More relevant to this study is the fact that both procedures were sensitive to findings that were significantly associated with aspiration pneumonia. One advantage of FEES was its ability to detect aspiration of secretions, a finding not available on fluoroscopy.

Only one measure of esophageal motility was found to be related to pneumonia, and none of the measures of gastroesophageal reflux were related to pneumonia. The lack of significant association between reflux and aspiration pneumonia is in disagreement with other studies that found a strong association between reflux and pneumonia [18,35-42]. However, these studies suggest that GE reflux is most dangerous in persons who are in the intensive care unit or in postsurgical units, two groups that we did not recruit. Only 97 subjects completed the scintigraphy studies, which reduced the power of our statistics. Also, although scintigraphy is a sensitive indicator of reflux [70-72], we did not use 24-hour $\mathrm{pH}$ monitoring, which is reported to be a more sensitive measure of reflux $[73,74]$. The current study should not be interpreted to mean that reflux is not a risk factor for pneumonia, but rather that there were methodological differences that could account for the findings.

The fact that reduced esophageal motility was significantly associated with development of pneumonia suggests that esophageal dysmotility, or slow and incomplete esophageal clearance, deserves more attention in dysphagia assessment. Reports in the literature indicate that esophageal dysmotility and pharyngeal dysphagia are common co-occurrences [75-77], suggesting that the two have a common pathophysiology. 
Feeding/Mode of Nutritional Intake. Tube feeding is generally implemented for patients who are severely dysphagic, debilitated, or malnourished and are unable to sustain their caloric and nutritional needs on an oral diet. In our study, tube feeding was significantly associated with aspiration pneumonia, which is consistent with the findings of others $[19,28,31-34,38,40]$. Because our patients were usually not taking any food or liquid by mouth, aspiration presumably occurred with secretions.

Oral/Dental Status. The number of decayed teeth and the frequency of brushing teeth and being dependent for oral care were significantly associated with pneumonia. These findings were consistent with our clinical impression that poor oral hygiene is common in hospitalized and nursing home patients. Vigild [78] reported that patients who needed assistance in toothbrushing had more plaque and gingivitis than those who brushed their own teeth. Similarly, Jette et al. [79] found a high correlation between oral disease and dependence for activities of daily living, including oral self-care among older persons. Others have documented that a relatively large proportion of the institutionalized, older, adult population has dental disease and that they rarely seek dental services [80].

Oral/dental disease may have been a contributing factor to pneumonia by increasing the levels of oral bacteria in the saliva, and/or by changing the composition of the salivary flora. Aspiration of the oropharyngeal secretions, mainly saliva, could explain the origin of many of the anaerobic bacteria that have been cultured from aspiration pneumonia $[43,45,81]$. Our finding that dental decay was associated with pneumonia in the bivariate analysis (Table 4) could mean that higher levels of certain bacteria, such as the mutans streptococci, lactobacilli, and yeast [82] were present in saliva, which could be added to any food, liquids, or secretions that would be aspirated.

\section{Predicting Aspiration Pneumonia}

From the multitude of significant factors found to be associated with pneumonia, we sought to identify the best independent predictors of pneumonia via multiple logistic regression analyses. These analyses revealed some interesting patterns. First, to our surprise, all the factors that directly measured dysphagia were eliminated as significant predictors. This does not necessarily imply that dysphagia and aspiration are not important, but suggests that these factors were highly correlated with other risk factors that had better predictive value, and that dysphagia by itself is not sufficient to cause pneumonia. In other words, dysphagia and aspiration may not be critical risk factors in a person who is medically stable, has a clean, healthy mouth, and/or is independent for daily activities, especially feeding. If a combination of these positive conditions are not met, however, pneumonia may develop.

At first glance, these results appear to contradict the many reports that have found dysphagia to be significantly associated with aspiration pneumonia. However, a closer look reveals that these studies usually only considered variables that fell within the domain of dysphagia. By not considering functional status, health status, and dental status, they limited the conclusions that could be reached. A similar criticism can be made of the multitude of research that has investigated variables that fell into one or two other domains, but did not consider dysphagia as a risk factor.

This role of dysphagia and aspiration in the pathogenesis of pneumonia may be better understood by considering the contributions of colonization and host resistance to the process. Aspiration must occur, but aspiration will only lead to pneumonia if the material aspirated is pathogenic to the lungs and if host resistance to the inoculum is compromised.

The bacterial flora in the oropharynx can be altered by severe underlying disease, inactivity, or malnutrition.[44,46,83,84] A more direct cause of altered colonization in the oropharynx is the presence of oral or dental disease. The shedding of bacteria from the buccal mucosa, tongue dorsum, gingival sulcus, and the teeth is about $10^{11}$ bacteria per day. Plaque, gingivitis, periodontal disease, and tooth decay will alter the flora within the mouth and could change the bacterial composition of saliva. Reduced salivary flow, a common side effect of many medications [85], increases the concentration of bacteria in the saliva [86], and if the saliva is aspirated, or more likely mixed with food or liquid, up to $100,000,000$ bacteria/ml saliva could enter the lungs. A person with dysphagia is more likely to aspirate in quantities that may far exceed $1 \mathrm{ml}$. These large-volume aspirations are of great concern, because any large chunks of food or otherwise insoluble material can obstruct the airways and, if not cleared, can set up a secondary infection, given the bacterial density of saliva. Clear liquids by themselves do not pose a problem, however, unless the $\mathrm{pH}$ is very high or low or if the volume is enough to cause asphyxia. ${ }^{2}$ The saliva drawn in with the liquid, on the other hand, may be problematic if it contains bacterial pathogens.

Nondysphagic persons may occasionally aspirate very small quantities of saliva/secretions, especially if they are lethargic, temporarily sedated, or perhaps when

${ }^{2}$ Persons with congestive heart failure have less effective lymphatic clearance of liquids (Curtis and Langmore; 1997). 
sleeping $[83,87]$. These nondysphagic persons could develop pneumonia if the concentration and composition of the oropharyngeal flora tended to select for putative respiratory pathogens. In this context the levels of Gramnegative enteric bacteria, including Pseudomonas and other opportunistic pathogens, increase in the salivary flora when there is poor oral hygiene, such as occurs postoperatively in an intensive care unit [88]. This phenomenon could be responsible for many cases of aspiration pneumonia in critically ill or intubated patients.

Once aspiration has occurred, host defenses must rally to clear the material. Cough and mucociliary clearance act to mechanically drive the material out of the lungs, and lymphatics and alveolar macrophages represent the cellular level of host response. Smoking, COPD, $\mathrm{CHF}$, or weak cough secondary to neurologic disease could all impair clearance, as would immunocompromised health status [13,89-91].

How do the results of the present study fit this model of pneumonia? In Figure 1, our significant predictors have been positioned in the model where they are thought to impact colonization and aspiration that can lead to pneumonia. First, two of our significant predictors for pneumonia could be related directly to oral/ dental disease and subsequent altered colonization of the oropharynx: dependent for oral care and number of decayed teeth. In addition, we believe that number of medications was probably associated with reduced salivary flow due to xerogenic effects of the medications, and that tube feeding was likely associated with poor oral hygiene and reduced salivary flow, because the person was not eating orally. All of these conditions presumably led to overgrowth of bacteria in the saliva, which, when mixed with food and/or liquid, could have provided a substantial bacterial inoculum to the lungs if aspirated. Ongoing studies are examining the saliva and throat flora of our subjects to determine whether any particular bacterial type can be associated with pneumonia.

Documented aspiration of food or liquid on an instrumental swallow study were not significant predictors of pneumonia. Sixty-nine percent of the patients who developed pneumonia aspirated food or liquid, suggesting that this finding would appear to be a fairly good predictor of pneumonia. However, of the patients who were documented aspirators, only about $38 \%$ developed pneumonia. Documented aspiration of food and liquid thus appear to be a sensitive, but not very specific predictor of aspiration pneumonia. ${ }^{3}$ Also, a substantial number of patients who were not observed to aspirate on an

\footnotetext{
${ }_{3}^{3}$ Documented aspiration of saliva was not a significant predictor either, but our interpretation of this finding is more tentative since relatively few subjects were given a FEES examination, the only examination that could have identified this event.
}

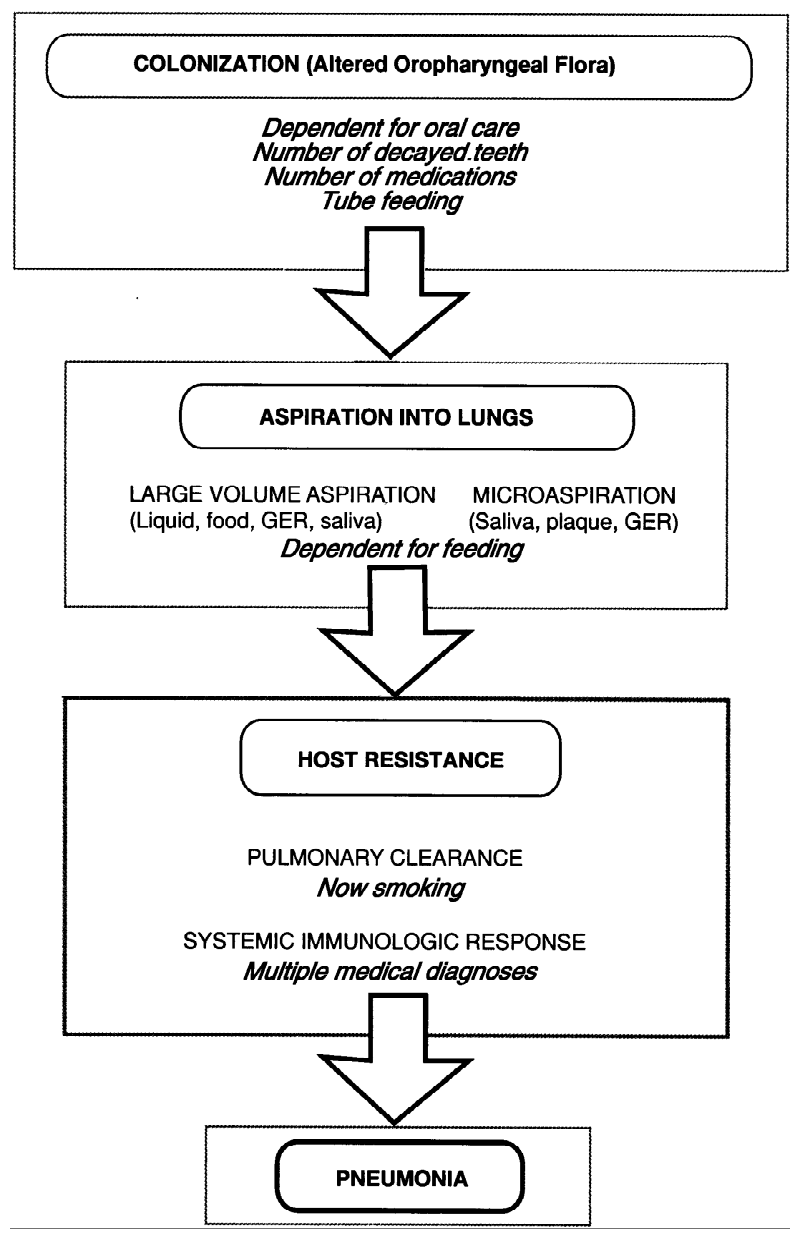

Fig. 1. Significant predictors of aspiration pneumonia (in bold italics) positioned in the model.

instrumental examination went on to develop pneumonia. Two possible explanations for this come to mind. Either the instrumental examination did not capture their real-life feeding ability or the persons who developed pneumonia were among those who experienced microaspiration, which would not have been detected in a formal swallowing study.

All patients with moderate or severe dysphagia were treated with conventional behavioral techniques and dietary changes to minimize any aspiration. However, our most significant predictor of pneumonia, dependent for feeding with an OR approaching 20 (Table 5), suggested that aspiration continued in some patients. Eighty-eight percent of the patients rated as dependent for feeding had dysphagia and $75 \%$ aspirated on an instrumental examination. Thus, many patients who were dependent for feeding were also dysphagic and especially prone to aspiration. In addition, there were a number of nondysphagic patients who may have aspirated when they were fed in states of fatigue, lethargy, inattention, or sedation. 
It has been observed that patients who cannot feed themselves are often fed by untrained nurses or aides who do not understand dysphagia and are under pressure to feed as many patients as they can in a short period of time. Thus, they unknowingly, by what may amount to force feeding, could cause the patient to aspirate some of the food and liquid they are feeding them, as well as the saliva that is mixed with the food and liquid. If the patients have dental decay that is symptomatic, this could further compromise chewing, thereby bringing larger boluses of food to the posterior pharynx.

Finally, impaired host resistance was implicated by two of our significant predictors of pneumonia. Now smoking suggested that pulmonary clearance was impaired in those subjects from reduced cough and mucociliary clearance [92]. Presence of multiple medical diagnoses may have reflected a greater severity of illness and an associated immunocompromise. Some of our significant predictors for colonization of the oropharynx, such as multiple medications, tube feeding, dependence for eating, and dependence for oral care, may have been associated with immunocompromise as well.

\section{Preventing Aspiration Pneumonia}

The implications of this study for effectively managing patients with dysphagia are clinically significant. Most speech-language pathologists have traditionally focused their therapy on postural changes, teaching swallow maneuvers, or instituting dietary alterations, so as to minimize pneumonia by making the swallow more effective. Our study suggests that an effective management program must go beyond direct treatment to improve the swallow. The fact that dependent for feeding was our best single predictor of pneumonia suggests that implementation of "safe feeding" techniques needs to be an integral part of dysphagia management. Addressing this risk factor should reduce the quantity of material aspirated, whether it be food, liquid, or saliva. Indirectly, it may improve nutritional status, and perhaps maximize host resistance. An example of such a program, where nurses and volunteers are taught to feed slowly and safely, is the Silver Spoons Program begun at the Miami VAMC [93].

Dependence for oral care in the all-subjects model with an OR of 2.8 (Table 5) was another strong predictor of aspiration pneumonia. Efforts to train nurses, family members, or volunteers to feed patients carefully ought to be paired with the teaching of better oral care so that caregivers can deliver both of these services effectively. This should be combined with dental treatment if there is any suspected dental disease. A program similar to this was described by Meguro et al. [94], with good preliminary results. The potential prob- lem of reduced salivary flow secondary to xerogenic medications should be directed to the patient's physician who might adjust some of the medications being taken by the patient.

Tube feeding is often the treatment of choice for a patient who aspirates on several consistencies of food. We found that tube feeding significantly increased the chances of developing aspiration pneumonia, perhaps because our patients continued to aspirate oropharyngeal secretions. Tube feeding promotes colonization because oral hygiene is often neglected in these patients and their salivary flow is often reduced. All tube-fed patients may microaspirate, especially if the tube is a large bore nasogastric tube, and the amount aspirated will likely be increased in the patient who has dysphagia. The best treatment strategy to prevent pneumonia in tube-fed patients might be one of aggressive oral hygiene and aggressive oral and pharyngeal suctioning of any excess secretions (and sometimes tracheal suctioning if the secretions are abundant). In addition, removing the tube and re-instituting careful oral feeding as soon as possible is recommended. Tube feeding may be the best treatment for some patients, but it probably ought to be viewed as a temporary management strategy more often than is seen in current clinical practice.

Finally, pulmonary clearance will be improved by increasing a patient's activity level and time spent out of bed; cessation of smoking will also help considerably. Postural adjustments and regular percussion and auscultation are suggested to aid pulmonary clearance. It is also important to keep the patient upright as much as possible during and after meals.

\section{Conclusion}

Aspiration pneumonia is a multifactorial phenomenon and no single predictor can cause this disease. A major conclusion was that dysphagia and aspiration are necessary but not sufficient conditions for development of pneumonia. Predictive risk factors falling under four major categories (medical/health status, oral/dental status, functional status, and swallowing/feeding status) were identified and significant predictors were explained in terms of their contribution to the pathogenesis of aspiration pneumonia. Dependence for feeding was a powerful predictor because it tends to increase the quantity of material aspirated, especially in patients with dysphagia. Since dependence for feeding is a marker for severely dependent functional status [67], it could be indirectly linked to malnutrition and perhaps an immunocompromised state as well.

In order to prevent pneumonia, we need to look beyond any single factor, such as dysphagia, and focus treatment on all relevant factors. The odds ratios for sig- 
nificant predictors derived in the current study may provide some guidance in this attempt. Some risk factors, such as dependence for feeding, were found to be especially potent predictors in this study and need to be given special attention in future studies to elucidate their exact relation to pneumonia. Further investigations are needed to identify other high risk variables that were not considered, for example, pulmonary clearance, measures of nutrition, or immunologic competence. It would also be extremely valuable to corroborate the present findings on a larger group of patients, expanded beyond the male, veteran population.

\section{References}

1. Zimmer JG, Bentley DW, Valenti WM, Watson NM: Systemic antibiotic use in nursing homes: a quality assessment. $J$ Am Geriatr Soc 34:703-710, 1986

2. Crossley KB, Thurn JR: Nursing home-acquired pneumonia. Semin Resp Infect 4:64-72, 1989

3. Horan TC, White JW, Jarvis WR, Emori TG, Culver DH, Munn VP, Thornsberry C, Olson DR, Hughes JM: Nosocomial infection surveillance 1980-1982. MMWR CDS Surveill Summ 35:17SS-29SS, 1986

4. Pugliese G, Lichtenberg DA: Nosocomial bacterial pneumonia: an overview. Am J Infect Control 15:249-265, 1987

5. Garibaldi RA, Brodine S, Matsumiya S: Infections among patients in nursing homes: policies, prevalence, and problems. $N E$ J Med 305(13):731-735, 1981

6. Bryan CS, Reynolds KL: Bacteremic nosocomial pneumonia: analysis of 172 episodes form a single metropolitan area. Am Rev Respir Dis 129:668-671, 1984

7. Wenzel RP: Hospital-acquired pneumonia: overview of the current state of the art for prevention and control. J Clin Microbiol Infect Dis 8:56-60, 1989

8. Marrie TJ, Durant H, Kwan C: Nursing home-acquired pneumonia: a case-control study. J Am Geriatr Soc 34:697-702, 1986

9. Alvarez S, Shell CG, Woolley TW, Berk SL, Smith JK: Nosocomial infections in long-term facilities. J Gerontol Med Sci 43:(1)M9-M17, 1988

10. Irvine PW, VanBuren N, Crossley K: Causes for hospitalization of nursing home residents: the role of infection. J Am Geriatr Soc 32(2): 103-107, 1984

11. Harkness GA, Bentley DW, Roghmann KJ: Risk factors for nosocomial pneumonia in the elderly. Am J Med 89:457-463, 1990

12. Mehr DR, Foxman B, Colombo P: Risk factors for mortality from lower respiratory infections in nursing home patients. $J$ Fam Pract 34:(5)585-891, 1992

13. Niederman MS: Nosocomial pneumonia in the elderly patient: pulmonary disease in the elderly patient. Clin Chest Med 14(3):479-490, 1993

14. Degelau J, Guay D, Straub K, Luxenberg MG: Effectiveness of oral antibiotic treatment in nursing home-acquired pneumonia. $J$ Am Geriatr Soc 43:245-251, 1995

15. Siebens H, Trupe E, Siebens A, Cook R, Anshen S, Hanauer R, Oster G: Correlates and consequences of eating dependency in institutionalized elderly. J Am Geriatr Soc 34:192-198, 1986

16. Rudman D, Feller AG: Protein-calorie undernutrition in the nursing home. J Am Geriatr Soc 37:173-183, 1989
17. Pingleton SK: Enteral nutrition as a risk factor for nosocomial pneumonia. Eur J Clin Microbiol Infect Dis 8:51-55, 1989

18. Ciocon JO, Silverstone FA, Graver LM, Foley CJ: Tube feedings in elderly patients: indications, benefits, and complications. Arch Int Med 148:105-108, 1993

19. Sitzmann JV: Nutritional support of the dysphagic patient: methods, risks, and complications of therapy. J Parenter Enter Nut 14(1):60-63, 1990

20. Terpenning MS: The 10 most common questions about aspiration pneumonia. Infect Dis 5(1):42-46, 1996

21. Schmidt J, Holas M, Halvorson K, Reding M: Videofluoroscopic evidence of aspiration predicts pneumonia and death but not dehydration following stroke. Dysphagia 9:7-11, 1994

22. Martin BJW, Corlew MM, Wood H, Olson D, Golopol LA, Wingo M, Kirmani N: The association of swallowing dysfunction and aspiration pneumonia. Dysphagia 9:1-6, 1994

23. Johnson ER, McKenzie SW, Sievers A: Aspiration pneumonia in stroke. Arch Phys Med Rehabil 74:973-976, 1993

24. Holas MA, DePippo KL, Reding MJ: Aspiration and relative risk of medical complications following stroke. Arch Neurol 51:1051-1053, 1994

25. Rogers B, Stratton P, Msall M, Andres M, Champlain MK, Koerner P, Plazza J: Long-term morbidity and management strategies of tracheal aspiration in adults with severe developmental disabilities. Am J Ment Retard 98(4):490-498, 1994

26. Taniguchi MH, Moyer RS: Assessment of risk factors for pneumonia in dysphagic children: significance of videofluoroscopic swallowing evaluation. Dev Med Child Neurol 36(6):495-502, 1994

27. Smithard DG, O'Neill PA, Park C, Morris J, Wyatt R, England R, Martin DF: Complications and outcome after acute stroke: does dysphagia matter? Stroke 27(7):1200-1204, 1996

28. Kidd D, Lawson J, Nesbitt R, MacMahon J: The natural history and clinical consequences of aspiration in acute stroke. $Q \mathrm{~J} \mathrm{Med}$ 88:409-413, 1995

29. Woratyla SP, Morgan AS, Mackay L, Bernstein B, Barba C: Factors associated with early onset pneumonia in the severely brain-injured patient. Conn Med (59)11:643-647, 1995

30. Harkness GA, Bentley DW, Roghmann KJ: Risk factors for nosocomial pneumonia in the elderly. Am J Med 89:457-463, 1990

31. Croghan JE, Burke EM, Caplan S, Denman S: Pilot study of 12-month outcomes of nursing home patients with aspiration on videofluoroscopy. Dysphagia 9:141-146, 1994

32. Gordon C, Langton-Hewer R, Wade DT: Dysphagia in acute stroke. Br Med J 295:411-414, 1987

33. Feinberg MJ, Knebl, J, Tully J: Prandial aspiration and pneumonia in an elderly population followed over 3 years. Dysphagia 11:104-109, 1996

34. Peck A, Cohen C, Mulvihill MN: Long-term enteral feeding of aged demented nursing home patients. J Am Geriatr Soc 38:1195-1198, 1990

35. Olson DL, Krubsack AJ, Stewart ET: Percutaneous enteral alimentation: gastrostomy versus gastrojejunostomy. Radiology 187:105-108, 1993

36. Pritchard V: Tube feeding-related pneumonias. J Gerontol Nurs 14(7):32-36, 1988

37. Cole MJ, Smith JT, Molnar C, Shaffer EA: Aspiration after percutaneous gastrostomy. J Clin Gastroenterol 9(1):90-95, 1987

38. Hassett JM, Sunby C, Flint LM: No elimination of aspiration pneumonia in neurologically disabled patients with feeding gastrostomy. Surg Gyncol Obstet 167:383-388, 1988

39. Dotson RG, Robinson RG, Pingleton SK: Gastroesophageal re- 
flux with nasogastric tubes: effect of nasogastric tube size. Am J Respir Crit Care Med 149:1659-1662, 1994

40. Olivares L, Segovia A, Revuelta R: Tube feeding and lethal aspiration in neurological patients: a review of 720 autopsy cases. Stroke 5:654-657, 1974

41. Sartori S, Trevisani L, Tassinari D, Nielsen I, Gilli G, Donati D, Malacarne P: Prevention of aspiration pneumonia during longterm feeding by percutaneous endoscopic gastrostomy: might cisapride play any role? Support Care Cancer 2:188-190, 1994

42. Tobin MJ: Aspiration pneumonia. In: Dantzker DR (ed.): Cardiopulmonary Critical Care. Orlando, FL: Grune and Stratton, 1986

43. Finegold SM: Aspiration pneumonia. Rev Infect Dis 13 (Suppl 9):S737-742, 1991

44. Verghese A, Berk SL: Bacterial pneumonia in the elderly. Medicine 62(5):271-285, 1983

45. Bartlett JG, Gorbach SL: The triple threat of aspiration pneumonia. Chest 68(4):560-566, 1975

46. Bartlett JG: Pneumonia. In: Hazzard WR, Bierman EL, Blass JP, Ettinger Jr WH, Halter JB (eds.): Principles of Geriatric Medicine and Gerontology. 3rd ed. New York: McGraw-Hill, 1994, pp 565-573

47. Mulligan R, Navazesh M: Relationship between oral conditions and systemic diseases in the elderly. J Dent Res 71 (Spec Issue) (Abstract) 1681:316, 1992

48. Johanson WG, Woods DE, Chaudhuri T: Association of respiratory tract colonization with adherence of gram-negative bacilli to epithelial cells. J Infect Dis 139(6):667-673, 1979

49. Johanson WG, Higuchi JH, Chaudhuri TR, Woods DE: Bacterial adherence to epithelial cells in bacillary colonization of the respiratory tract. Am Rev Respir Dis 121:55-63, 1980

50. Valenti WM, Trudell RG, Bentley DW: Factors predisposing to oropharyngeal colonization with gram-negative bacilli in the aged. N Engl J Med 298(20):1108-1111, 1978

51. Terpenning M, Bretz W, Lopatin D, Langmore S, Dominguez B, Loesche W: Bacterial colonization of saliva and plaque in the elderly. Clin Infect Dis 16(Suppl 4):S314-S316, 1993

52. Horner J, Massey EW, Riski JE, Lathrop DL, Chase KN: Aspiration following stroke: clinical correlates and outcome. $\mathrm{Neu}$ rology 38:1359-1362, 1988

53. Logemann JA, Pauloski BR, Rademaker A, Cook B, Graner D, Milianti F, Beery Q, Stein D, Bowman J, Lazarus C, Heiser MA, Baker T: Impact of the diagnostic procedure on outcome measures of swallowing rehabilitation in head and neck cancer patients. Dysphagia 7:179-186, 1992

54. DePippo KL, Holas MA, Reding MJ, Mandel FS, Lesser ML: Dysphagia therapy following stroke: a controlled trial. Neurology 44:1655-1660, 1994

55. Neumann S, Bartolome G, Buchholz D, Prosiegel M: Swallowing therapy of neurologic patients: correlation of outcome with pretreatment variables and therapeutic methods. Dysphagia 10:1-5, 1995

56. Crary M: A direct intervention program for chronic neurogenic dysphagia secondary to brainstem stroke. Dysphagia 10:6-18, 1995

57. Langmore SE, Schatz K, Olsen N: Fiberoptic endoscopic examination of swallowing safety: a new procedure. Dysphagia 2:216-219, 1988

58. Loesche WJ, Abrams J, Terpenning MS, Bretz WA, Dominguez BL, Grossman NS, Hildebrandt GH, Langmore SE, Lopatin DE: Dental findings in geriatric populations with diverse medical backgrounds. Oral Surg Oral Med Oral Pathol 80:43-54, 1995

59. Anderson HA, Holman CB, Olsen AM: Pulmonary complications of cardiospasm. JAMA 151:608-612, 1953
60. Urschel HC, Paulson DL: Gastroesophageal reflux and hiatal hernia: complications and therapy. J Thorac Cardiovasc Surg 53:21-32, 1967

61. Iverson LIG, May IA, Samson PC: Pulmonary complications in benign esophageal disease. Am J Surg 126:223-228, 1973

62. Marumo K, Homma S, Fukuchi Y: Postgastrectomy aspiration pneumonia. Chest 107(2):453-456, 1995

63. Albright JR, Rytel MW: Bacterial pneumonia in the elderly. $J$ Am Geriat Soc 28:220-225, 1980

64. Davis AL, Grobon EJ, Tompset R, McClement JH: Bacterial infection and some effects of chemoprophylaxis in chronic pulmonary emphysema. Am Rev Respir Dis 92(6):900-913, 1965

65. Bentley DW: Pneumococcal vaccine in the institutionalized elderly: review of past and recent studies. Rev Infect Dis 3:S61-S70, 1981

66. Bynum LJ, Pierce AK: Pulmonary aspiration of gastric contents. Am Rev Respir Dis 114:1129-1136, 1976

67. Katz S, Akpom A: A measure of primary sociobiological functions. Int J Health Serv 6(3):493-508, 1976

68. Perlman AL, Booth BM, Grayhack JP: Videofluoroscopic predictors of aspiration in patients with oropharyngeal dysphagia. Dysphagia 9:90-95, 1994

69. Murray J, Langmore SE, Ginsberg S, Dostie A: The significance of accumulated oropharyngeal secretions and swallowing frequency in predicting aspiration. Dysphagia 11:99-103, 1996

70. Fisher RS, Malmud LS, Roberts GS, Lobis IF: Gastroesophageal (GE) scintiscanning to detect and quantitate GE reflux. Gastroenterology (70)3:301-308, 1976

71. Malmud LS, Fisher RS: Radionuclide studies of esophageal transit and gastroesophageal reflux. Semin Nucl Med 12(2): 104-115, 1982

72. Velasco N, Pope CE, Gannan RM, Roberts P, Hill LD: Measurement of esophageal reflux by scintigraphy. Dig Dis Sci 29(11):977-982, 1984

73. DeMeester TR, Want CI, Wernly JA, Pellegrini CA, Little AG, Klementschitsch P, Bermudez G, Johnson LF, Skinner DB: Technique, indications, and clinical use of 24-hour esophageal pH monitoring. J Thorac Cardiovasc Surg 79:656-670, 1980

74. Vitale GC, Sadek S, Tulley FM, Rimmer AR, Hunter BE, Phelan J, Cuschieri A: Computerized 24-hour esophageal $\mathrm{pH}$ monitoring: a new ambulatory technique using radiotelemetry. $J \mathrm{Lab}$ Clin Med 105:686-693, 1985

75. Jones B, Ravich WJ, Donner MW, Kramer SS: Pharyngoesophageal interrelationships: observations and working concepts. Gastroenterol Radiol 10:225-233, 1985

76. Jones B, Ravich WJ, Donner MW, Rubesin SE, Ravich WJ, Hendrix TR: Pharyngeal findings in 21 patients with achalasia of the esophagus. Dysphagia 2:87-92, 1987

77. Sivit CJ, Curtis DJ, Crain M, Cruess DF, Winters C: Pharyngeal swallow in gastroesophageal reflux disease. Dysphagia 2:151-155, 1988

78. Vigild M: Oral hygiene and periodontal conditions among 201 dentate institutionalized elderly. Gerodontics 4:140-145, 1988

79. Jette AM, Feldman HA, Douglass C: Oral disease and physical disability in community-dwelling older persons. J Am Geriatr Soc 41:1102-1108, 1993

80. Beck JD: Epidemiology of periodontal disease in older adults. In: Ellen RP (ed.): Periodontal Care for Older Adults. Toronto, Canada: Canadian Scholars' Press Inc., 1992, pp 9-35

81. Rosen S, Elvin-Lewis E: Oral microflora In: Willett NP, White RR, Rosen S (eds.): Essential Dental Microbiology. Norwalk: Appleton \& Lange, 1991, pp 318-340

82. Loesche WJ, Shork A, Terpenning MS, Chen YM, Stoll J: Fac- 
tors which influence levels of selected organisms in saliva of older individuals. J Clin Microbiol 33(10):2550-2557, 1995

83. Bartlett JG, Finegold SM: Anaerobic infection of the lung and pleural space. Am Rev Respir Dis 110:56-77, 1974

84. Johanson WG, Pierce AK, Sanford JP: Changing pharyngeal flora of hospitalized patients emergence of gram-negative bacilli. N Engl J Med 281:1137-1140, 1969

85. Sreebny LM, Valdini A: Xerostomia a neglected symptom. Arch Intern Med 147:1333-1337, 1987

86. Loesche WJ, Bromberg J, Terpenning MS, Bretz WA, Dominguez MS, Grossman MA, Langmore SE: Xerostomia, xerogenic medications and food avoidances in selected geriatric groups. JAGS 43:401-407, 1995

87. Huxley EJ, Viroslav J, Gray WR, Pierce AK: Pharyngeal aspiration in normal adults and patients with depressed consciousness. Am J Med 64:564-568, 1978

88. Woods DE, Straus DC, Johanson Jr WG, Bass JA: Role of salivary protease activity in adherence of gram-negative bacilli to mammalian buccal epithelial cells in vivo. J Clin Invest $68: 1435-1440,1981$
89. Curtis JL, Langmore SE: Respiratory function in its relation to deglutition. In: Perlman AL, Schulze-Delrieu K (eds.): Deglutition and its Disorders. San Diego: Singular Press, 1997

90. Skerrett SJ: Host defenses against respiratory infection. Med Clin North Am. 78(5):941-966, 1994

91. Dhar S, Shastri SR, Lenora RAK: Aging and the respiratory system. Symposium on Geriatric Medicine. Med Clin North Am 60(6):1121-1139, 1976

92. Goodman RM, Yergin BM, Landa JF: Relationship of smoking history and pulmonary function tests to tracheal mucus velocity in nonsmokers, young smokers, ex-smokers, and patients with chronic bronchitis. Am Rev Respir Dis 117:205-214, 1978

93. Musson ND, Kincaid J, Ryan P, Glussman B, Varone L, Gamarra N, Wilson R, Reefe W, Silverman M: Nature, nurture, nutrition: interdisciplinary programs to address the prevention of malnutrition and dehydration. Dysphagia 5:96-101, 1990

94. Meguro K, Yamagauchi CD, Nakamura T, Sekizawa K, Sasaki $\mathrm{H}$ : Prevention of respiratory infections in elderly bed-bound nursing home patients. Tohoku J Exp Med 167:135-142, 1992 